\title{
Sustainable Product Portfolio Evaluation Methodology for Sustainability Reporting in the Cement and Concrete Industry
}

\author{
Christian Artelt ${ }^{1, *}$, Peter Lukas ${ }^{1}$
}

\begin{abstract}
The sustainability performance of companies, and in particular of construction material producers, is attracting more and more attention by a broad range of stakeholders. Many companies have consequently started to implement sustainability practices into practical action and to report on their efforts. This research aims to develop a methodology to assess the sustainability performance of cement and concrete products. This requires overcoming the main shortage of life cycle assessment, namely focusing on environmental parameters only, by considering a number of social and economic sustainability indicators and ensuring operational ease, without compromising the informative value of the assessment results. A status on sustainable product evaluation is provided as the starting point for the development of the new sustainable product evaluation methodology. The status on product evaluation includes Life Cycle Assessments, the development of indicators addressing environmental, social, and economic parameters, and recent methodology developments in industry. The results obtained with the tool developed in this work confirm the need for considering social and economic parameters along a product's life cycle when evaluating the sustainability performance of cement and concrete. They also indicate that the new methodology is suitable for R\&D orientation, portfolio management and sustainability reporting.
\end{abstract}

Keywords: Sustainable products, sustainability indicators, lifecycle, UN Sustainable Development Goals, financial data

\section{Introduction}

Life cycle assessment (LCA) has a long history in the cement and concrete industry (Young et al. 2002, Josa et al. 2007) resulting into the publication of numerous environmental product declarations (e.g. IBU 2019). LCA focusses on the systematic analysis of environmental impacts of products. Social and economic impacts as typical for cement and concrete production are not addressed.

At the same time, the overall sustainability performance of construction material producers is attracting more and more attention by a broad range of stakeholders, including authorities, civil society, shareholders and investor community. An increasing number of investors, analysists and rating agencies consequently sees, besides economic performance also environmental, social and governance related criteria as important KPIs to describe a company's performance. In fact, institutional investors increasingly use compliance with such KPIs as investment decision support tool (Speich, 2019 a, b). In the light of this, the turnover realized with "sustainable products" has become an important KPI for many investors, analysts and rating agencies. 
Profound academic research (e.g. Hallstedt, 2017, Fritz et al., 2018) led to the development of approaches to determine relevant sustainability indicators for all three sustainability dimensions, and some industrial players, in particular from the chemical (BASF, 2018) and consumer goods' industry (Schröder et al., 2015) developed own approaches to evaluate the sustainability performance of their comprehensive product portfolio. Unfortunately, none of these approaches is universal and can be directly used to perform sustainability evaluations of cement and concrete where the room for radical product innovation and short term commercialization is far more limited. In the light of this, the purpose of this paper is to develop a sustainable product evaluation methodology that is particularly suitable for the cement and concrete industry.

The so-called Product-Evaluation Tool, or in short "PET-Tool", presented in this paper addresses environmental, social and economic parameters along a product's life cycle. At the same it ensures operational ease, without compromising the informative value of the assessment results.

With implementing this product evaluation methodology, HeidelbergCement complies with its stakeholders' requests for transparent sustainability data. A broad range of sustainability data is already published in the HeidelbergCement Group Annual Sustainability Report (HeidelbergCement 2018 a) and is now complemented by information regarding the annual turnover realized with sustainable products.

\section{Status Quo of Sustainable Product Evaluations}

\subsection{Life Cycle Assessments (LCA) and Environmental Product Declarations (EPD)}

LCA is defined as the systematic analysis of the environmental impact of products during their entire life cycle. During a life cycle assessment environmental impacts are evaluated throughout the entire life cycle of a product (production, use and disposal phases). This also includes the upstream and downstream processes associated with the production (e.g. production of raw, auxiliary and operating materials) and with the disposal (e.g. waste treatment). Environmental impacts refer to all relevant extractions from the environment (e.g. ores and crude oil), as well as emissions into the same (e.g. wastes and carbon dioxide). The International Organization for Standardization provides guidelines for conducting a life cycle assessment according to ISO 14040 and ISO 14044. If the impacts that are quantified via life cycle assessment are also third party validated, the outcome is a so-called Environmental Product Declaration, or EPD. Principles and procedures of EPDs are described in ISO 14025. Core rules for EPDs addressing construction products are specified in EN 15804.

Lifecycle assessment is applied in the cement and concrete sector (GCCA, 2019) and EPDs are also available (IBU 2019). However, as cement and concrete production takes place at large number of production sites, assessing social and economic impacts - not covered by LCA/EPD - is also very important. The applicability of LCA/EPDs for the sector is therefore limited.

\subsection{Defining sustainability indicators addressing the environmental, social and economic dimension}


Evaluating the sustainability performance of a given product in all three sustainability dimensions - environmental, social and economics (United Nations, 1987) requires defining a broader set of indicators than covered by LCA. A number of very different approaches were proposed over the past decades; among them:

Veleva and Ellenbecker (2001) proposed a comprehensive eight step model to identify and implement a framework of 22 core- and 8 supplemental indicators of sustainable production. The indicators refer to six main aspects of sustainable production previously defined by the Lowell Center for Sustainable Production (LCSP), namely 1) energy and material use (resources); 2) natural environment (sinks); 3) social justice and community development; 4) economic performance; 5) workers; and 6) products. The indicators are classified along five categories of complexity, ranging from measuring the extent to which a facility or company is in compliance with regulations or in conformance to industry/association standards (level one) to showing how an individual company's production process fits into the larger picture of a sustainable society (level five).

De Silva et al. (2006) defined six sustainability elements, namely 1) product's environmental impact; 2) societal impact; 3) functionality; 4) resource utilization and economy; 5) manufacturability; and 6) recyclability/re-manufacturability. The authors came up with a framework of 44 influencing factors addressing 24 sub-elements. Together with their industrial partner they developed a scoring model validated through a case study on a laser printer that permits to establish a sustainability ranking for two different products addressing the same purpose. A rating system leading to a product sustainability index was also proposed by Jawahir et al. (2006) and developed further as a metrics-based framework to evaluate the total life cycle sustainability of manufactured products (Zhang et al. 2012, Shuaib et al., 2014).

More recent work, such as of Hallstedt (2017), Mesa et al. (2018) or Fritz et al. (2017) visibly include the product's lifecycle perspective. In a process based on a comprehensive literature review and a broad stakeholder consultation including industry, NonGovernmental Organizations (NGOs), government officials, interest groups and researchers, Fritz et al. (2017) came up with a set of 36 sustainability aspects for the supply chain-wide sustainability assessment in the automotive and electronics industries. The set of aspects is covering environmental, social and governance aspects.

Even though some of the approaches were developed in cooperation with industrial partners, their commercial implementation remains limited.

\subsection{Sustainable Product Evaluations in Industry}

Instead, some industrial players developed their own set of tools to perform sustainable product evaluations. These tools incorporate elements of previous research, such as a life-cycle perspective and, in many cases, are used for the management of a sustainable product portfolio (Villamil and Hallstedt, 2018).

Henkel, a prominent company in the consumer goods industry follows a stage-gate based innovation process that includes benchmarking the sustainability profile of a new product against state-of-the art. The so-called Henkel Sustainability\#Master ${ }^{\circledR}$ (Schröder et al., 2015) is a matrix that permits to measure product performance along two dimensions: 1) 
along six individual life-cycle steps of the value chain, namely raw materials, production, logistics, retailing, service/use and disposal and 2) Henkel's six focal areas addressing value and footprint, respectively.

BASF (BASF, 2018) and Clariant (CSCP and Clariant, 2015), both leading chemical companies, developed and implemented similar stage-gate based innovation process: BASF's "Sustainable Solution Steering" starts with a check for basic sustainability requirements. If no critical issues are identified, a check for the sustainability value contribution of the new product is performed. This check addresses the whole product's lifecycle and provides answer if there is a substantial contribution to at least one sustainability criterion, thereby without significantly compromising the performance in other criteria. The Sustainable Product Steering process permits classifying products within four distinct categories. Finally, a very similar portfolio management process is performed by Clariant where selected products receive a dedicated labeling.

The product portfolio of cement and ready-mixed concrete producers is usually less diversified than the portfolio of chemical companies or of companies producing consumer goods. Furthermore, the portfolio of cement and concrete producers is largely determined by existing standards, such as EN 197-1 and EN 206-1. Room for radical product innovation and short term commercialization is consequently far more limited. This is why the use of well developed, sophisticated product assessment and development tools other than carbon calculators (Hanson, 2019) or traditional lifecycle assessment (GCCA, 2019) focusing on a broader range of environmental impacts are not yet common in these industries. However, stakeholder requests for transparent, holistic sustainability data including social and economic aspects have become common (e.g. Speich, 2019 a, b) and inspired HeidelbergCement to develop the so-called Product-Evaluation Tool, or in short "PET-Tool".

\section{PET-Tool}

The PET-Tool was developed as a method to assess the sustainability performance of products, namely of cement and concrete. Purpose of the approach was to overcome the main shortage of life cycle assessment, namely to focus on environmental parameters along a product's life cycle without addressing the social and economic dimension of sustainability. At the same time focus was laid on ensuring operational ease, without compromising the informative value of the assessment results.

The PET-Tool consists of two main elements: The PET-questionnaire, and the Database of Sustainable Product (DSP).

The questionnaire compares for a given application the sustainability performance of a new product against state-of-the art technology. The "new" product is a cement type or a type special concrete with improved sustainability characteristics. It is benchmarked against the "base" product which, for a given application, is the most commonly used product in 2018, or in other words the "state-of-the art". Typical cement applications are ready-mixed concrete or precast, and for concrete industrial flooring or general construction.

The DSP consolidates key sustainability performance data and financial data such as volumes / tonnages produced, and revenue of all identified sustainable products and 
provides information on the aggregated turnover realized with sustainable products.

\section{PET-Questionnaire Development}

The PET-questionnaire was developed in a thorough, multi-stage process as shown in Figure 1.

\begin{tabular}{c|c} 
Step 1 & Problem statement \\
Step 2 & Sustainability dimensions \\
\hline Step 3 & Sustainability categories \\
Step 4 & Aspects \\
\hline Step 5 & Overview matrix \\
\hline Step 6 & Sustainability Indicators \\
\hline Step 7 & Questionnaire \\
\hline
\end{tabular}

Figure 1: Development approach of the PET questionnaire

Step 1: Problem statement

As first step the problem statement (Fritz et al., 2017) was defined. A problem statement serves to clearly specify the challenge that needs to be solved. In the case of a cement and concrete producer, building on the statement "develop a concept enabling the relative sustainability performance comparison of two cement types or types of concrete used in the same application" allows to identify all products with better sustainability performance than the respective state-of-the art. Based on the outcome of these evaluations it is a straightforward process to determine, in a later step, the turnover realized with sustainable products.

Step 2: Sustainability dimension

Sustainability is defined through three different, interconnected sustainability dimensions or pillars: environmental, social, and economic (United Nations, 1987). Cement and concrete production both relate to all three pillars (e.g. HeidelbergCement, 2018 a). Furthermore, the implementation of management systems is a transversal category that largely determines a company's sustainability performance (Wang et al., 2016). It was therefore decided to build the PET-questionnaire on the following four dimensions: environmental, social, economic, and management systems.

Step 3: Sustainability categories

This step serves to capture relevant sustainability categories (Fritz et al., 2017) that relate to the four dimensions of sustainability identified in step 2. Table 1 shows an excerpt of the sustainability categories relevant for cement and concrete and relating to the sustainability dimensions environmental, social, economic, and management.

Table 1: Excerpt of the sustainability categories relevant for cement and concrete and relating to the four sustainability categories environmental, social, economic, and management 


\begin{tabular}{|ll|}
\hline Dimension & Sustainability category \\
\hline Management & Quality \\
& Environment \\
& Energy \\
& Occupational health and safety \\
& Supply chain \\
\hline Environmental & Raw materials \\
& Fuels \\
& Energy \\
& Emissions \\
& Water \\
\hline Social & Emissions \\
& Working conditions \\
\hline Economic & Profitability \\
& Expenses \\
\hline
\end{tabular}

Some of the categories are interconnected, such as for example energy and emissions. Furthermore, it may happen that an individual category addresses more than one sustainability dimension ( $\mathrm{Lu}$ et al. 2011). This is the case for emissions which relate to the environmental and the social category.

Step 4: Aspect

An aspect is a parameter that serves to describe a given sustainability category. Capturing the entire scope of a sustainability category and considering the time based dimension, namely the lifecycle, often require defining more than one aspect for the respective sustainability category (De Silva et al., 2006, Fritz et al. 2017). An overview on aspects describing environmental sustainability categories relating to cement and concrete is given in table 2 .

Table 2: Overview on aspects describing environmental sustainability aspects relating to cement and concrete

\begin{tabular}{|lll|}
\hline Sustainability dimension & Category & Aspect \\
\hline Environment & Raw materials & $\begin{array}{l}\text { Secondary raw materials for clinker production } \\
\text { Recycled and secondary materials in the final product }\end{array}$ \\
\cline { 2 - 3 } & Fuels & Secondary fuels \\
\hline Energy & Energy required for production \\
& Energy consumption during use phase \\
\cline { 2 - 3 } & Emissions & $\mathrm{CO}_{2}$ emissions during production \\
& $\mathrm{CO}_{2}$ emissions during transportation \\
& $\mathrm{CO}_{2}$ emissions during use phase \\
\cline { 2 - 3 } & Fresh water consumption during production \\
\hline
\end{tabular}

Main environmental aspects include secondary raw materials in clinker production, recycled and secondary material content in the final product, secondary fuel rate, $\mathrm{CO}_{2}$ emissions in different lifecycle phases and fresh water consumption during production. Aspects were also identified for the sustainability dimensions management, social and economic.

The preliminary outcome was discussed with a broad range of internal stakeholders with background in sustainability, product development, communication, and operations, and was then adjusted according to the feedback obtained. An important advice was to keep the number of aspects as low as possible to ensure applicability of the system under industrial constraints. It was recommended to focus on a relevant, but limited set of core 
aspects that, preferably, HeidelbergCement would be able to assess on its own. For many aspects relating to the construction and use phase this is either not the case, or can be done in a qualitative manner only: Energy consumption and $\mathrm{CO}_{2}$ emissions during construction are mostly determined by construction companies' activities and the values are not accessible for construction material producers.

Step 5: Overview matrix

The target of this step was to arrange the selected aspects in a matrix along the two axis life-cycle and sustainability dimension (Schröder et al., 2015). Figure 2 provides a simplified high-level overview of the different lifecycle phases of a construction material, here readymixed concrete (RMC).

RMC is produced in a batching plant and transported to the construction site by truck. The truck is equipped with a slowly rotating drum to ensure that the concrete does not segregate and is delivered to the construction site in a workable state. At the construction site of a building the RMC is casted to form the base plate, structural elements, walls, or other elements. Once the construction phase is completed it is followed by the use phase which can be as long as 100 years in the case of concrete buildings (Kurkinen et al., 2015). End-of-life of a building leads to a number of options. Deconstruction can be followed by landfill or - far more preferable - by recycling into new construction materials that will undergo a second life application.
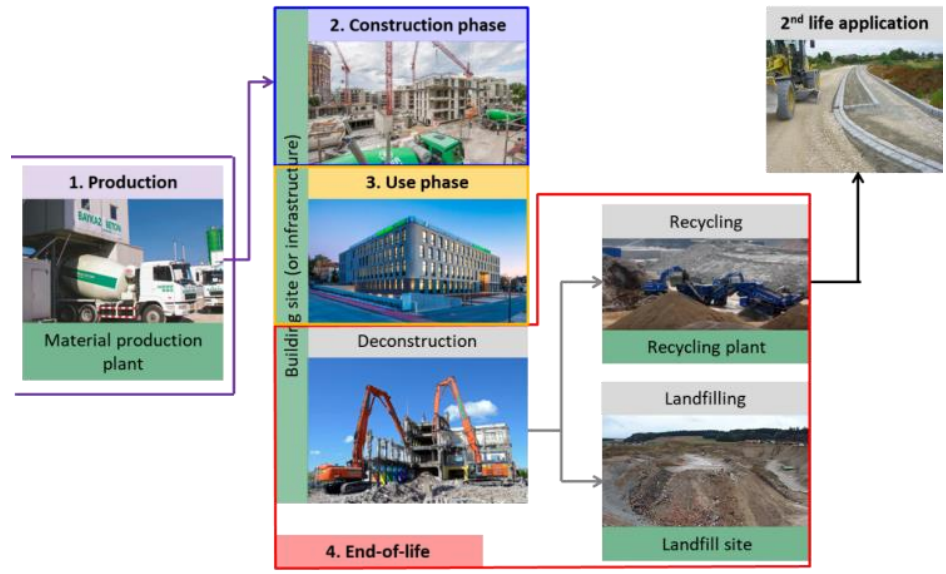

Figure 2: Lifecycle phases of ready-mixed concrete

Previous studies (Becke et al, 2014; Bellmann and Zimmermann, 2019) have shown that in the case of cement and ready-mixed concrete - the environmental impact of transportation is of secondary order. It was therefore decided not to consider this part of the lifecycle. Concerning the end of life phase it was assumed that recycling costs would be a reasonable measure for the recyclability. This is confirmed by current tipping fees in Germany (AWG, 2019 a; AWG, 2019 b) for different classes of C\&DW. Consequently, no "environmental" aspect was included into the matrix for this lifecycle phase. Based on these assumptions the overview matrix of the aspects was derived and is shown in Table 3.

Table 3: Two dimensional overview matrix of the aspects along the axis life-cycle and sustainability dimension 


\begin{tabular}{|c|c|c|c|c|c|}
\hline Dimension / Phase & Management Systems & Production & Construction & Use & End of life \\
\hline Management & $\begin{array}{c}\text { Quality } \\
\text { Environment } \\
\text { Energy } \\
\text { H\&S } \\
\text { Responsible sourcing }\end{array}$ & & & & \\
\hline Environmental & & $\begin{array}{l}\text { Secondary fuels } \\
\text { Secondary raw materials for } \\
\text { dinker production } \\
\text { Recyced and secondary materials } \\
\text { in the final product } \\
\text { Energy } \\
\text { Co2 emissions } \\
\text { Fesh water } \\
\end{array}$ & & $\begin{array}{l}\text { CO2 emissions } \\
\text { Environmental benefit }\end{array}$ & \\
\hline Social & & & $\begin{array}{l}\text { Physical effort } \\
\text { vocemissions } \\
\text { Noise }\end{array}$ & Social benefit & \\
\hline Economic & & Margin & Construction works & Economic benefit & Deconstuction and recycling \\
\hline
\end{tabular}

Step 6: Indicators

After assigning all sustainability aspects identified in Step 4 to a specific sustainability dimension in a given live cycle phase (Step 5, Table 3), relevant and "measureable" indicators needed to be identified for each of the aspects. Good data access- and availability permits to provide numerical values in many cases. This applies to cement and concrete production data being collected by producers without any intermediary. Indicators relating to the construction and use phase can be captured in relative terms only, i.e. the indicator is "higher", "similar" or "lower" (h/s/l) than for a given base product, or by means of a simple "yes/no" (y/n) query. This is because the data is either not numerically captured, or it is not accessible for the construction material producer.

Table 4: Two dimensional overview matrix of the indicators along the axis life-cycle and sustainability dimensions

\begin{tabular}{|c|c|c|c|c|c|}
\hline Dimension / Phase & Management Systems & Production & Construction & Use & End of life \\
\hline Management & $\begin{array}{c}\operatorname{QMS}(y / n) \\
\operatorname{EMS}(y / n) \\
\operatorname{Energy}(y / n) \\
\operatorname{H\& SMS}(y / n) \\
\text { RSS }(y / n)\end{array}$ & & & & \\
\hline Environmental & & $\begin{array}{l}\text { Secondary fuels rate }(\%) \\
\text { Secondary raw materials during } \\
\text { clinker production (\%) } \\
\text { Recycled and secondary material } \\
\text { content the final product } \\
\left(\mathrm{kg} / \mathrm{m}^{3}, \mathrm{~kg} / \mathrm{t} \text { or } \%\right) \\
\text { Energy requirement } \\
\left(\mathrm{kWh} / \mathrm{t}, \mathrm{MJ} / \mathrm{t} \text { or } \mathrm{MJ} / \mathrm{m}^{3}\right) \\
\mathrm{CO}_{2} \mathrm{emiss} \text { ions } \\
\left(\mathrm{kgCO} / \mathrm{t} \text { or } \mathrm{kgCO} / \mathrm{m}_{2}\right)^{3} \\
\text { Fesh water demand }(\mathrm{l} / \mathrm{t})\end{array}$ & & $\begin{array}{l}\mathrm{CO} 2 \text { emissions }(\mathrm{h} / \mathrm{s} / \mathrm{l}) \\
\text { Environmental beneficial } \\
\text { application }(\mathrm{y} / \mathrm{n})\end{array}$ & \\
\hline Social & & & $\begin{array}{l}\text { Physical effort }(\mathrm{h} / \mathrm{s} / \mathrm{l}) \\
\text { voC emissions }(\mathrm{h} / \mathrm{s} / \mathrm{l}) \\
\text { Noise emissions }(\mathrm{h} / \mathrm{s} / \mathrm{l})\end{array}$ & Social valuable application $(y / n)$ & \\
\hline Economic & & $\operatorname{Margin}(\mathrm{h} / \mathrm{s} / \mathrm{l})$ & Site work related costs $(\mathrm{h} / \mathrm{s} / \mathrm{l})$ & Economic performance $(y / n)$ & $\begin{array}{l}\text { Decons tuction and recycling } \\
\qquad \cos t 5(\mathrm{~h} / \mathrm{s} / \mathrm{l})\end{array}$ \\
\hline
\end{tabular}

The two dimensional indicator matrix relevant for cement and concrete is shown in Table 4: Indicators refer to 
- the application of management systems;

- environmental sustainability and profitability during production;

- social indicators during construction addressing workers' and neighbors' concerns, and site work related costs;

- selected indicators during use phase addressing environmental, social, and economic matters;

- and deconstruction and recycling costs at the end of life phase.

Step 7: Questionnaire

Purpose of the final step was to transform the overview matrix of indicators into a questionnaire. This was achieved by phrasing, for each indicator, a framing question, i.e. for

Management systems (MS):

- MS.1: Do you have a quality management system in place?

- MS.2: Do you have an environmental management system in place?

- MS.3: Do you have an energy management system in place?

- MS.4: Do you have a health and safety management system in place?

- MS.5: Do you have a responsible sourcing system in place?

Production (Prod):

- Prod.1: What is the secondary fuel rate during clinker production?

- Prod.2: What is the secondary raw material content during clinker production?

- Prod.3: What is the product's recycled and secondary material content?

- Prod.4: What is the amount of energy required to produce the product?

- Prod.5: What is the $\mathrm{CO}_{2}$ emission during production?

- Prod.6: How high is the fresh water demand during production?

- Prod.7: When compared to the base product - is the margin of the new product lower, similar or higher?

Construction phase (CP):

- CP.1: When compared to the base product - does placing the new product require less, similar of higher physical effort?

- CP.2: When compared to the base product - does the new product release less, similar of higher noise emissions during the construction phase?

- CP.3: When compared to the base product - does the new product lead to less, similar or higher noise emissions during the construction phase?

- CP.4: When compared to the base product - are site work related costs lower, similar or higher?

Use phase (UP):

- UP.1: When compared to the base product - is the new product causing higher, similar or less $\mathrm{CO}_{2}$ emissions during use phase?

- UP.2: Is the primary purpose of the product and environmental beneficial one?

- UP.3: Is the primary purpose of the product a social valuable application?

- UP.4: When compared to the base product - is the economic performance of the new product lower, similar or higher?

End-of-life (Eol):

- Eol.1: When compared to the base product - are deconstruction and recycling costs 
and/or landfilling costs lower, similar, or higher?

To ensure credibility of the results, the PET-questionnaire requires that solid evidence is provided with each answer, and - if applicable - that the corresponding data base is stated.

\section{Alignment with the "UN Sustainable Development Goals"}

The PET-questionnaire's alignment with the UN Sustainable Development Goals (United Nations, 2015) was verified and the result is shown in Figure 3: The questionnaire covers 12 out of the 17 UN Sustainable Development Goals (SDG). Implementing traditional management systems, i.e. quality-, environmental-, energy-, and health and safety management addresses some of the targets specified in SDG "3 Good health and well-being", "7 Affordable and clean energy", "12 Responsible consumption and production", and "15 Life on land". However, implementing a responsible sourcing management system, such as offered by the Concrete Sustainability Council (CSC, 2019) is an effective way to adopt a more holistic sustainable management approach and to comply with a far broader range of SDGs.

During production phase the targets of a number of SDGs are addressed, namely of "6 Clean water and sanitation", "7 Clean and affordable energy", "8 Decent work and economic growth", "12 Responsible consumption and production", "13 Climate action", and "15 Life on land". This is fully coherent with HeidelbergCement's Sustainability Commitments 2030: As a leading cement, aggregate and concrete producer, HeidelbergCement commits to "reducing the environmental footprint" and "enabling the circular economy", and these commitments also address the same production related SDGs (HeidelbergCement, 2018 b).

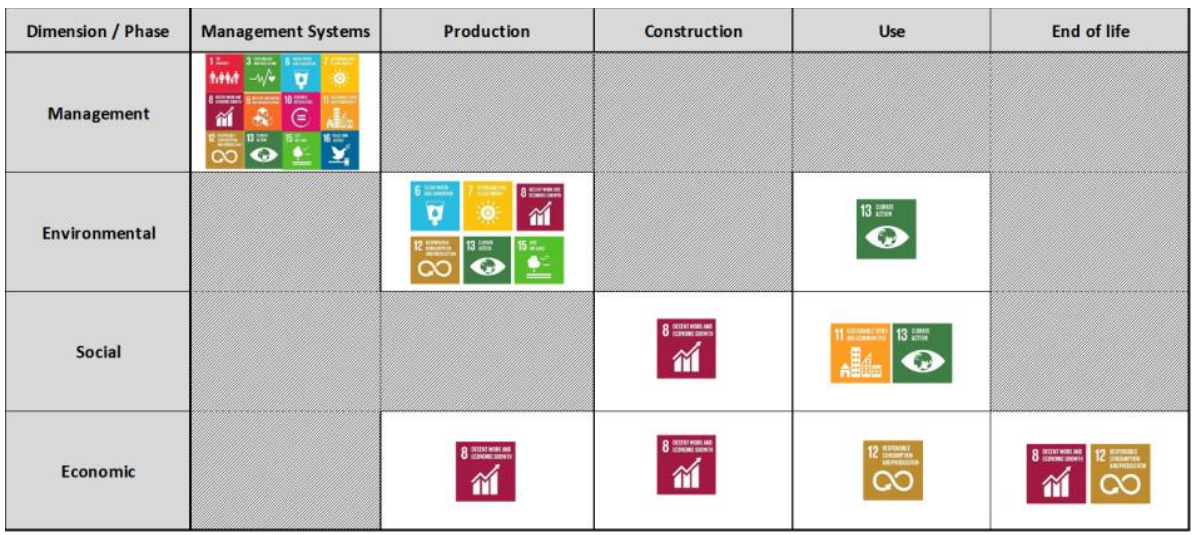

Figure 3: Sustainability indicators' coverage of the UN Sustainable Development Goals

Construction, use and end of-life are out of the direct control of the construction material producer. Still, the PET-questionnaire considers these phases by means of addressing indicators that consider SDG "8 Decent work and economic growth", "11 Sustainable cities and communities", "12 Responsible consumption and production", and "13 Climate action". 


\section{Sustainability Product Performance Score}

When developing a new methodology of evaluating product sustainability over the total lifecycle, Jawahir et al. (2006) proposed to merge all sustainability elements into a product sustainability index. A dedicated scoring model was also proposed by De Silva et al. (2006) when comparing the sustainability performance of different laser printers. Similarly, the PET-tool uses a dedicated scoring model to aggregate the assessment results into a single Sustainability Product Performance Score (SPPS). The scoring model assigns a fixed weight, represented by a specific number of points to each of the sustainability indicators previously identified and addressed in the PET questionnaire in form of a dedicated question. The points that are assigned to each indicator are "earned" by the product with the lower (unwanted) impact or the higher benefit. The points are equally split if the impact or benefit is the same, or - in the case of qualitative answers - similar. The weight of each indicator was assigned in line with the materiality analysis recently performed by HeidelbergCement (HeidelbergCement, 2018 a).

The SPPS consequently adds up from a well-defined weight of each of the "Sustainability Dimension / Phase"-couples (see Table 5).

Table 5: Weight of the sustainability indicators and the respective "Sustainability Dimension / Phase"'-couples

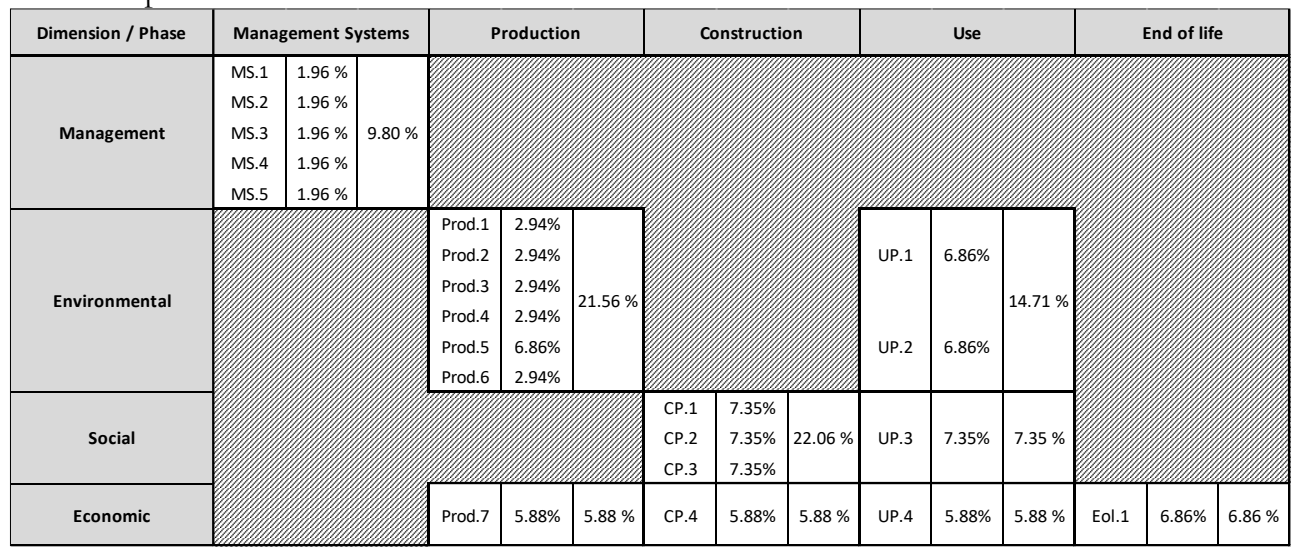

A "new product" is considered as a sustainable product if its SPPS is higher than the SPPS of the "base product" representing state-of-the art technology in 2018. Applying this strict methodology ensures that the sustainability performance data generated with the PETtool meets the requirements for obtaining external assurance (GRI, 2013).

\section{Results}

Prior to rolling out the PET-methodology to HeidelbergCement country organizations, the applicability of the methodology and the meaningfulness of the results were tested for a range of different products. This section provides an exemplary evaluation of a cement and a concrete product in a given country.

Cement 
The exemplary evaluation addresses two cement types used in civil engineering in a European country. CEM I 42.5 N with moderate heat of hydration, low alkali content and high sulfate resistance was the by far most common cement type used in civil engineering in this county in 2018 and was consequently assigned as the base product. CEM II/A-V $42.5 \mathrm{~N}$, also with moderate heat of hydration and low alkali content is another cement type used for civil engineering in the same country, but in significantly lower volumes. CEM II/A-V is assigned as the "new product" and benchmarked against the CEM I. The results of the product benchmarking are shown in Figure 4:

\begin{tabular}{|c|c|c|c|c|c|}
\hline $\begin{array}{l}\text { Dimension / } \\
\text { Phase }\end{array}$ & $\begin{array}{l}\text { Management } \\
\text { Systems }\end{array}$ & Production & Construction & Use & End of life \\
\hline Management & $\Rightarrow$ & & & & \\
\hline Environmental & & & & $\Rightarrow$ & \\
\hline Social & & & $\Rightarrow$ & $\Rightarrow$ & \\
\hline Economic & & $\Rightarrow$ & $\Rightarrow$ & $\Rightarrow$ & $\Rightarrow$ \\
\hline
\end{tabular}

Figure 4: New product performance compared to base product

The management systems are the same as both products are produced at the same plant. The difference in sustainability performance is related to a number of environmental indicators relating to the production phase, i.e. the products' recycled and secondary material content, the energy required for production, and the production related $\mathrm{CO}_{2}$ emissions. Due to the higher clinker content of the CEM I (see EN 197-1) overall energy consumption and production related $\mathrm{CO}_{2}$ emissions are higher. This is confirmed by EPDs that were prepared for both products (see IBU 2019). Furthermore, the CEM I only contains marginal amounts of recycled/secondary materials as part of the raw meal, whereas the CEM II/A-V additionally contains significant amounts of fly ash that are added during the cement grinding step. None of the environmental, social and economic indicators addressing construction, use phase and end of life leads to appreciable differences as the cement types' behavior is similar and without measurable impact on these indicators.

The products' SPPS is shown in Figure 5: The new product CEM II/A-V turns out to be the more sustainable product in the application civil engineering. The CEM II/A-V is consequently considered as a sustainable product and hence contributes to HeidelbergCement's turnover realized with sustainable products. 


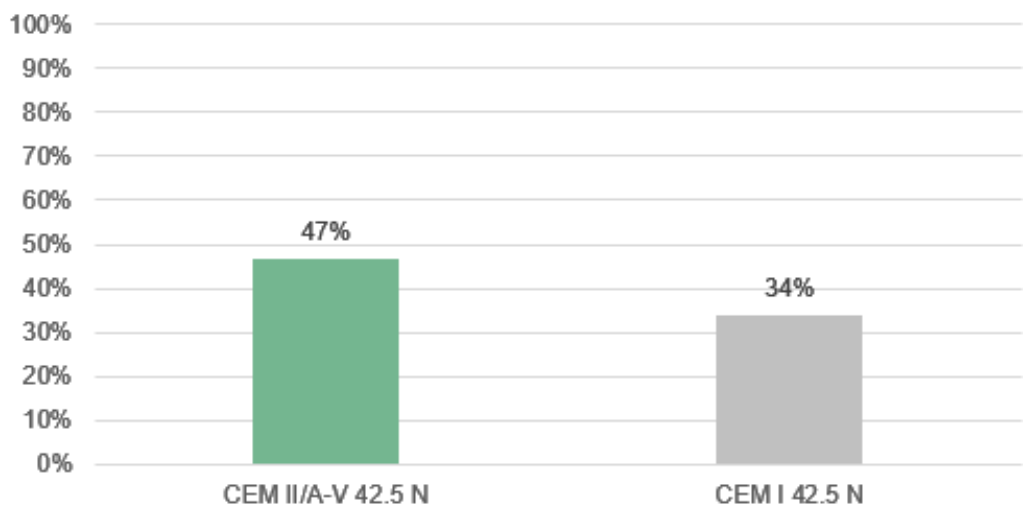

Figure 5: SPPS of the two cements evaluated according to the PET-methodology

Cementitious screeds

The exemplary evaluation addresses self-compacting cementitious screed in another European Country. The self-compacting screed (= "New Product") is benchmarked against a traditional cementitious screed (= "Base Product") of the same strength class, but characterized by significantly less fluidity. The market share of self-compacting cementitious screeds has increased over the past year, but is still less than the share of traditional cementitious screeds which are commonly used in humid environments where the use of gypsum based screeds is problematic. The results of the product benchmarking are shown in Figure 6:

New Product performance compared to Base Product

\begin{tabular}{|c|c|c|c|c|c|}
\hline $\begin{array}{c}\text { Dimension / } \\
\text { Phase }\end{array}$ & $\begin{array}{c}\text { Management } \\
\text { Systems }\end{array}$ & Production & Construction & Use & End of life \\
\hline \multicolumn{6}{|l|}{ Management } \\
\hline \multicolumn{6}{|l|}{ Environmental } \\
\hline \multicolumn{6}{|l|}{ Social } \\
\hline Economic & & & & & \\
\hline
\end{tabular}

Figure 6: New product performance compared to base product

The self-compacting cementitious screed and the traditional cement based screed are produced in the same plant. The underlying management systems are consequently the same. The difference in environmental performance during production is related to the following indicators: the products' recycled and secondary material content, $\mathrm{CO}_{2}$ emissions and the amount of fresh water required for production: The self-compacting cementitious screed's recipe requires more cement than the traditional cement based screed's recipe. Furthermore, the self-compacting screed is produced with Portland cement (CEM I), while traditional cement based screeds usually contain Portland slag cement (CEM II). When producing the self-compacting cementitious screed, the fresh water requirement is also higher. This is primarily caused by the higher cement content 
and because recycled water cannot be used for production. However, as the selfcompacting cementitious screed is typically used in combination with floor heating, its excellent flowing behavior leads to an enhanced embedding of the heating pipes. Visibly less air pockets significantly improve heating efficiency during use phase (IWM, 2016; DIN 4108-4). As a consequence of this, heating related $\mathrm{CO}_{2}$ emissions and costs will be reduced. Regarding the social dimension: Self-compacting cementitious screeds can be placed with significantly less physical effort. The self-compacting properties also reduce noise emissions as the need for compaction vibrations is eliminated. From a financial perspective, self-compacting cementitious screeds are an attractive solution for the producer, but also for the construction company as the construction efficiency is significantly improved. The replacement of traditional cementitious screeds by selfcompacting cementitious screeds has no measurable impact on the end of life phase.

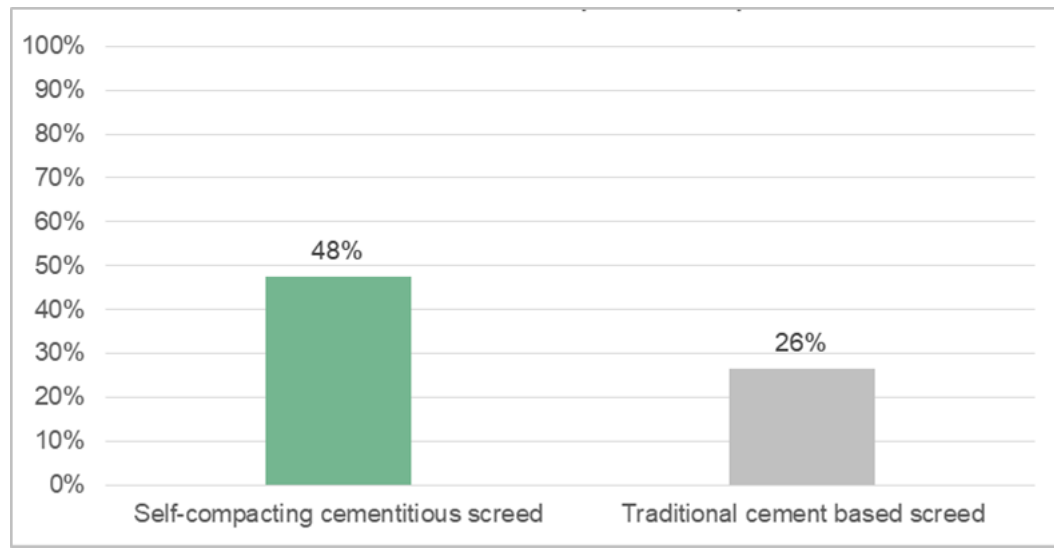

Figure 7: SPPS of self-compacting cementitious screed and traditional cementitious screed when evaluated according to the PET-methodology

The product evaluation performed according to the PET-methodology enables assessing the different sustainability aspects along the product's whole life cycle and to aggregate the different impacts into an overall score by means of the underlying scoring-model. The products' SPPS is shown in Figure 7: Self-compacting cementitious screeds are evaluated as sustainable products: The lower environmental performance during production is outbalanced by the product's sustainability benefits, namely the added social value during construction, contribution to reducing a building's heating requirement during use phase, and the economic performance. The sales of self-compacting cementitious screeds therefore contributes to HeidelbergCement's turnover realized with sustainable products.

\section{Summary and Conclusions}

The PET-tool developed in this work is a tool to assess the sustainability performance of products, namely of cement and concrete. It overcomes the main shortage of life cycle assessment, namely to focus on environmental parameters only. PET also addresses a number of social and economic sustainability indicators along a product's life 
cycle, thereby ensuring operational ease, without compromising the informative value of the assessment results.

PET-evaluations were performed for HeidelbergCement's cement and concrete portfolio on 2018 data in Germany, the Netherlands, Belgium, Norway, Sweden, Poland, and the Czech Republic. The key sustainability performance data of the products evaluated was consolidated into the Database of Sustainable Products (DSP) and, therein, combined with the respective financial data, i.e. volumes / tonnages produced, and revenue. The turnover realized in 2018 with sustainable products as defined by the PET-methodology was determined as $11.43 \%$ within the scope of evaluation. The value was third party approved, at the level of limited assurance. This was achieved through a comprehensive external assessment of the PET-methodology and the collected data, respectively. The data was published for the first time in HeidelbergCement's 2018 Group Sustainability Report (HeidelbergCement, 2018 a).

Assessing the turnover realized with sustainable products is important for HeidelbergCement in the context of its stakeholder dialogue. Reporting this performance indicator has consequently become an integral part of the company's Group Sustainability Report. To further improve data quality, the underlying data base will be enlarged over the next years by including non-European target countries into the scope of evaluation.

Applying the PET-methodology presented in this work to R\&D helps providing orientation to projects and is a strong lever to steer the company's future portfolio. Given its commitment to spend $80 \%$ of the product related R\&D budget on the development of more sustainable products (HeidelbergCement, 2018 b), HeidelbergCement is confident that the turnover realized with sustainable product will continue to increase over the next years.

\section{Abbreviations}

$\begin{array}{ll}\text { CSC } & \text { Concrete Sustainability Council } \\ \text { C\&DW } & \text { Construction and demolition waste } \\ \text { DSP } & \text { Database of sustainable products } \\ \text { EMS } & \text { Energy management system } \\ \text { EnMS } & \text { Energy management system } \\ \text { EPD } & \text { Environmental product declaration } \\ \text { GCCA } & \text { Global Cement and Concrete Association } \\ \text { GRI } & \text { Global Reporting Initiative } \\ \text { H\&SMS } & \text { Health and safety management system } \\ \text { LCA } & \text { Life cycle assessment } \\ \text { PET } & \text { Product evaluation tool } \\ \text { RMC } & \text { Ready-mixed concrete } \\ \text { RSS } & \text { Responsible sourcing system (e.g. Concrete Sustainability Council - CSC) } \\ \text { SCC } & \text { Self-compacting concrete } \\ \text { SDG } & \text { UN Sustainable Development Goal } \\ \text { SPPS } & \text { Sustainability Product Performance Score } \\ \text { QMS } & \text { Quality management system }\end{array}$

\section{References}


AWG Abfallwirtschaft Landkreis Calw G, (2019 a): Merkblatt zur Verwertung und Entsorgung von Baustellenabfällen insbesondere von „Mineralischen Abfällen“ (Bauschutt). https://www.awginfo.de/fileadmin/Dateien/AWG/Dateien/Merkblaetter/Baustellenabfaelle_Abbruchmaterial.pdf . Accessed 25/10/2019

AWG Abfallwirtschaft Landkreis Calw G (2019 b): Merkblatt Recyclinghöfe und Entsorgungsanlagen Gebühren und Mengenbegrenzungen. https://www.awginfo.de/fileadmin/Dateien/AWG/Dateien/Merkblaetter/AWB Gebuehren und Mengenbegren zungen.pdf. Accessed 25/10/2019

BASF (2018): Sustainable Solution Steering. https://www.basf.com/global/de/who-we-are/sustainability/wedrive-sustainable-solutions/sustainable-solution-steering.html. Accessed 16/10/2019

Becke, A., Reiners, J., Sülün, C. (2015): Erläuterungen zu den Umweltproduktdeklarationen für Beton. InformationsZentrum Beton Gmbh, Erkrath

Bellmann, E., Zimmermann, P. (2019): Klimaschutz in der Beton- und Zementindustrie. WWF Deutschland, Berlin

Concrete Sustainablity Council (2019): Concrete Sustainablity Council technical manual - Version 2.0. https://www.concretesustainabilitycouncil.com/concrete-sustainability-council-technical-manualversion-20-34. Accessed 28/10/2018

Collaborating Centre on Sustainable Consumption and Production (CSCP), Clariant International Ltd (2015): Developing Tools for Sustainable Product Portfolio Management. https://www.scpcentre.org/wp-content/uploads/2017/03/Clariant Portfolio Value Program Case Study.pdf. Accessed 16/10/2019

De Silva, N., Jawahir, I., Dillon Jr., O., Russell, M. (2006): A new comprehensive methodology for the evaluation of product sustainability at the design and development stage of consumer electronic products. 13th CIRP International Conference on Life Cycle Engineering, Heverlee, Belgium. Proceedings of LCE 2006, 335 -340

DIN 4108-4: DIN Normenausschuss Bauwesen (2017): Thermal insulation and energy economy in buildings - Part 4: Hygrothermal design values

EN 15804: European Committee for Standardization (2011): Sustainability of construction works Environmental product declarations - Core rules for the product category of construction products

EN 197-1: European Committee for Standardization (2011): Composition, specifications and conformity criteria for common cements

EN 206-1: European Committee for Standardization (2001): Concrete Specification, performance, production and conformity

Fritz, M., Schöggl, J.-P., Baumgartner, R. (2017): Selected sustainability aspects for supply chain data exchange: Towards a supply chain-wide sustainability assessment. Journal of Cleaner Production 141, 587-607

GCCA (2019). GCCA EPD Tool. See https://gccassociation.org/sustainability-innovation/environmentalproduct-declarations/. Accessed 15/12/2019

Global Reporting Initiative GRI (2013): The external assurance of sustainability reporting. https://www.globalreporting.org/resourcelibrary/GRI-Assurance.pdf. Accessed 29/10/2019

Hanson (2019): Link to Hanson (HeidelbergCement Group) carbon concrete calculator: see https://www.hanson.co.uk/en/tools/concrete-carbon-calculator. Accessed 15/12/2019

Hallstedt, S. (2017): Sustainability criteria and sustainability compliance index for decision support in product development. Journal of Cleaner Production 140, 251-266

HeidelbergCement (2018 a): Group Sustainability Report 2018, https://www.heidelbergcement.com/en/sustainability-reports. Accessed 15/12/2019

HeidelbergCement (2018 b): Sustainability 2030. https://www.heidelbergcement.com/en/sustainability-commitments-2030. Accessed 15/12/2019

IBU (2019): Institut Bauen und Umwelt e.v., Publised EPDs; see: https://ibu-epd.com/en/published-epds/. Accessed 13/12/2019

ISO 14025: International Organization for Standardization (2006): Environmental labels and declarations Type III environmental declarations - Principles and procedures

ISO 14040: International Organization for Standardization (2006): Environmental management — Life cycle assessment — Principles and framework 
ISO 14044: International Organization for Standardization (2006): Environmental management - Life cycle assessment - Requirements and guidelines

IWM (2016): Zementfließestich - Hinweise für die Planung und Ausführung. Industrieverband Werkmörtel e.V., Duisburg, Germany. Downloaded on 04/12/2019 from https://www.vdpm.info/services/downloads/broschueren-und-merkblaetter/\#estrich

Jawahir, I., Dillon Jr, O., Rouch K., Joshi, K., Venkatachalam, A., Jaafar, I. (2006): Total life-cycle considerations in product design for sustainability: a framework for comprehensive evaluation. Proceedings of the $10^{\text {th }}$ international research/expert conference TMT, Barcelona, Spain, 2006, 1 10

Josa, A., Aguado, A., Cardim, A., Byars, E. (2007): Comparative analysis of the life cycle impact assessment of available cement inventories in the EU. Cement and Concrete Research 37, 781-788

Kurkinen, E.-L., Norén, J.Peñaloza, D., Al-Ayish, N., During, O. (2015): Energy and climate-efficient construction systems. SP Rapport 2015:70 E. SP Svierges Tekniska Forskningsinstitut, Boras, Sweden

Lu T., Gupta, A., Jayal, A., Badurdeen, F., Feng, S., Dillon Jr., O., Jawahir, I. (2011): A Framework of Product and Process Metrics for Sustainable Manufacturing. In: Seliger G., Khraisheh M., Jawahir I. (eds) Advances in Sustainable Manufacturing. Springer, Berlin, Heidelberg

Mesa, J., Esparragoza, I., Maury, H. (2018): Developing a set of sustainability indicators for product families based on the circular economy model. Journal of Cleaner Production 196, 1429-1442

Schröder, F., Holbach, D., Müller-Kirschbaum, T. (2015): Henkel: Sustainability in the value chain: From philosophy to practice. In Michael D'heur: Sustainable value chain management, Springer, 249-259

Shuaib, M., Badurdeen, F., Rouch, K., Feng, S., Jawahir, I (2014). Product Sustainability Index (ProdSI) - A Metrics Based Framework to Evaluate the Total Lifecycle Sustainability of Manufactured Products. Journal of Industrial Ecology, 18, 4, 491-507

Speich, I. (2019 a): Wir werden Firmen aussortieren. Handelsblatt, 12/07/2019. https://www.handelsblatt.com/finanzen/banken-versicherungen/ingo-speich-im-interviewchefstratege-der-deka-bank-wir-werden-firmen-aussortieren/24582180.html?ticket=ST-41870794BXWhTrs1Q69EsvtkedTv-ap5. Accessed 12/11/2019

Speich, I. (2019 b): ESG-Investing: MiFID II als Game-Changer. E-fundresearch.com, 02/09/2019. https://e-fundresearch.com/funds/artikel/36237-esg-investing-mifid-ii-als-gamechanger?region $=$ de. Accessed 15/12/2019

United Nations (1987): Report of the World Commission on Environment and Development. Our common futures

United Nations (2015): Transforming our world: The 2030 agenda for sustainable development. https://sustainabledevelopment.un.org/content/documents $/ 21252030 \% 20$ Agenda $\% 20$ for $\% 20$ Su stainable \%20Development $\% 20$ web.pdf. Accessed 28/10/2019

Veleva, V., Ellenbecker, M. (2001): Indicators of sustainable production: framework and methodology, Journal of Cleaner Production 9, 519-549

Villamil, C., Hallstedt, S. (2018): Sustainability Product Portfolio: A Review. European Journal of Sustainable Development 7, 4, 146-158

Wang, X., Lin, H., Weber, O. (2016): Does adoption of management standards deliver efficiency gain in firms pursuit of sustainability performance? An empirical investigation of Chinese manufacturing firms. Sustainability 2016, 8, 694-711

Young, S., Turnbull, S. Russel, A. (2002): Towards a Sustainable Cement Industry. What LCA can tell us about the Cement Industry. World Business Council for Sustainable Development

Zhang, X., Lu, T., Shuaib, M., Rotella, G., Huang, A., Feng, S., Rouch, K., Badurdeen, F. and Jawahir, I. (2012). A metrics-based methodology for establishing product sustainability index (ProdSI) for manufactured products. In Leveraging Technology for a Sustainable World (Edited by D. A. Dornfeld and B. S. Linke), 435-441. Springer Publishers 